\title{
Sobre la importancia de contextualizar las investigaciones en didáctica de las ciencias
}

\author{
José María Oliva \\ Editor de la revista.josemaria.oliva@uca.es. \\ ORCID: https://orcid.org/0000-0002-2686-6131
}

Editorial: About the importance of contextualizing science education researchs

Para citar este artículo: Oliva J. $\mathrm{M}^{\mathrm{a}}$ (2020) Sobre la importancia de contextualizar las investigaciones en didáctica de las ciencias. Revista Eureka sobre Enseñanza y Divulgación de las Ciencias 17(1), 1001. doi: 10.25267/Rev_Eureka_ensen_divulg_cienc.2020.v17.11.1001

Desde la perspectiva académica, suele considerarse importante para una revista científica que una parte significativa de los artículos publique sean de investigación. No en vano muchas bases de datos y directorios de revistas imponen este requisito a las revistas que aspiran a ser indexadas. En el ámbito concreto de la enseñanza de las ciencias, lo que caracteriza a un manuscrito como de investigación suele consistir en la recopilación, tratamiento y exposición de información procedente del objeto de estudio, en el marco de un problema o de una pregunta planteada: diagnósticos, estudios de caso, evaluación de cambios, análisis comparativos, etc. Es evidente que la incorporación de estas dinámicas investigadoras, que han se contemplarse además desde algún referente teórico, ha supuesto un importante vector de avance para la educación científica, al aportar valores que se complementan con los de innovación y diseño didáctico, presentes en la práctica docente.

Sin embargo, observamos cómo en muchos de los artículos de investigación que llegan a Revista Eureka sobre Enseñanza y Divulgación de las Ciencias (REurEDC), se prima la descripción y discusión en torno a los datos obtenidos, frente al análisis y caracterización del escenario didáctico que sirve de soporte. Así, suele ser usual que se omitan detalles importantes sobre el(los) planteamiento(s) didáctico(s) de referencia o se dedique a ellos un espacio puramente testimonial. Ello incluso en casos en los que el contexto es relevante y supone el núcleo central del propio artículo: evaluar una propuesta didáctica concreta, analizar los beneficios de una determinada estrategia de enseñanza, comparar dos diseños metodológicos diferentes, etc. Hemos de recordar que, en esos casos, el tratamiento y exposición de información empírica requiere de una adecuada definición del escenario didáctico de fondo. De lo contrario, no sólo se subestima la importancia del diseño o de la propuesta didáctica implicada, sino que se minusvalora la propia esencia de la investigación, así como el interés del manuscrito presentado.

Sensible a esta problemática, REurEDC ha intentado potenciar una mayor presencia explícita, en los artículos que publica, de los diseños y propuestas didácticas de referencia, en aquellas investigaciones en las que el contexto didáctico es relevante. Para ello, desde hace tiempo, sus normas de publicación recogen la posibilidad de incluir, como material complementario, la caracterización completa o transcripción de dichos materiales: "Al objeto de contextualizar mejor el contenido de los trabajos, en determinados casos será posible publicar, como material complementario, detalles específicos de las propuestas didácticas o de los instrumentos de evaluación implicados..."

Con ello, se pretende contribuir a una investigación en didáctica de las ciencias más y mejor contextualizada. Queremos aprovechar estas líneas para reiterarnos en estos principios y renovar nuestra invitación a los autores para hacer uso de esta posibilidad.

\author{
Revista Eureka sobre Enseñanza y Divulgación de las Ciencias \\ Universidad de Cádir. APAC-Eureka. ISSN: 1697-011X \\ http:/ / dx.doi.org/10.25267/Rev_Eureka_ensen_divulg_cienc.2020.v17.i1.1001 \\ http:/ / reuredc.uca.es
}

